\title{
Preparation of rare-earth-free oxide glass phosphors
}

\author{
Hirokazu MASAI ${ }^{\dagger}$ \\ Institute for Chemical Research, Kyoto University, Gokasho, Uji, Kyoto 611-0011, Japan
}

\begin{abstract}
Light emission in rare earth (RE)-free $\mathrm{SnO}-\mathrm{ZnO}-\mathrm{P}_{2} \mathrm{O}_{5}$ glasses is demonstrated. The RE-free transparent phosphate glasses show light emission with high quantum efficiency $(\mathrm{QE})$ values, comparable to conventional crystalline phosphors, by excitation with deep-UV light. The broad emissions of the RE-free transparent glasses can be continuously tuned by both the amount of activator and the composition of the glasses, without reduction of the $Q E$ values. For future emitting devices, we believe that the lowmelting glasses will constitute one of the most industrially favorable inorganic materials possessing transparency and emitting properties.
\end{abstract}

(C)2013 The Ceramic Society of Japan. All rights reserved.

Key-words : Glass, Emission, Sn, Phosphor, Rare earth free

[Received October 1, 2012; Accepted November 29, 2012]

\section{Introduction}

Recently, the strong, sharp emissions of rare earth (RE) cations have been used in the white light-emitting diodes (LED). ${ }^{1)}$ Since conventional fluorescent lamp containing $\mathrm{Hg}$ vapor generates heat, the trend shifts to LED that has much longer lifetime compared with the conventional devices. However, there are mainly two problems in the blue and UV LED applications shown in Fig. 1. First point is low color rendering. White lightemitting devices comprising the sharp emission bands of REs usually have the problem of color rendering that is lower than conventional broadband emission devices. Second is the device structure. Although various kinds of RE-doped phosphors have been actively developed worldwide, the host materials (sealant) for these phosphors, such as silicone, still remain limited with respect to high-power or short-wavelength excitation light sources, because of degradation. Thus, a novel, inorganic, lowmelting material will be needed as an alternative to organic sealing materials in the future. In addition, RE-free materials have been extensively examined because there is uncertainty about the stability of RE supplies in the future. If a transparent glass material without a RE cation emits white light comparable to a crystalline phosphor, it would be considered a novel emitting material capable of good formability, which is quite important in the industrial manufacturing process. In addition, the emission color can also be widely tuned because various kinds of emission centers can be incorporated in the glass network, which is quite different from the conventional RE-doped crystalline phosphor. Therefore, we have focused our efforts on RE-free glass phosphors that can be used in white fluorescent lamps.

Since white light emission is composed of various wavelengths, it can be attainable by RE-free phosphors: for example, the $\mathrm{Sb}^{3+}, \mathrm{Mn}^{2+}$-doped calcium halophosphate, $\left[\mathrm{Ca}_{5}\left(\mathrm{PO}_{4}\right)_{3}(\mathrm{~F}, \mathrm{Cl})\right.$ : $\left.\mathrm{Sb}^{3+}, \mathrm{Mn}^{2+}\right]^{2)}$ In the halophosphate crystal, broad white light emission is attained using $\mathrm{Sb}^{3+}$ and $\mathrm{Mn}^{2+}$ cations, in which the emission of $\mathrm{Mn}^{2+}$ cation is sensitized by $\mathrm{Sb}^{3+}$ cations via an energy transfer process. Although several cations have been used

\footnotetext{
Corresponding author: H. Masai; E-mail: masai_h@noncry.kuicr. kyoto-u.ac.jp
}

\begin{tabular}{l|l|l}
\hline & Conventional type & Target \\
\hline & & \\
\hline Uhosphor & Rare earth-doped crystal & Oxide glass \\
\hline sealant & Polymer or Silicone & Oxide glass \\
\hline
\end{tabular}

Fig. 1. (Color online) Schematic image of white LEDs: conventional type and the target of the present study.

as an emission center, it is necessary to select an emission center exhibiting the parity allowed excitation, i.e. the high transition probability, to attain high performance for practical application using amorphous materials. Therefore, we have selected $\mathrm{ns}^{2}$-type emission center, which possesses the allowed transition, and lowmelting phosphate glass to prepare a next generation emitting materials. In the following sections, $\mathrm{ns}^{2}$-type emission center is first introduced before our recent results. Secondly, results of low-melting phosphate glasses containing $\mathrm{Sn}^{2+}$ emission center are shown. Thirdly, the author compares emission properties of two $\mathrm{ns}^{2}$-type emission centers: $\mathrm{Sn}^{2+}$ and $\mathrm{Sb}^{3+}$. Finally, demonstration of white light emission using $\mathrm{Sn}^{2+}$ and $\mathrm{Mn}^{2+}$ cations is described.

\section{Luminescence of $n s^{2}$-type emission center}

The ns ${ }^{2}$-type ions $(n=4,5,6)$ is a technical term of ions exhibiting $\mathrm{ns}^{2}$ electron configuration in the ground state and $n s^{1} \mathrm{np}^{1}$ in the excited state. Table 1 shows several $\mathrm{ns}^{2}$-type ions whose emission property has been reported in alkali halides ${ }^{3)-7)}$ and several oxides. ${ }^{2), 8)-17)}$ In particular, excitation and emission spectra of $\mathrm{Tl}^{+}$-incorporated alkali halides have been most minutely reported. ${ }^{3), 4)}$ The characteristics of theses ions are (1) parity allowed excitation $\left({ }^{1} \mathrm{~S}_{0} \rightarrow{ }^{1} \mathrm{P}_{1}\right)$, and spin-forbidden relaxation $\left({ }^{3} \mathrm{P}_{1} \rightarrow{ }^{1} \mathrm{~S}_{0}\right)$ whose decay is the order of microseconds, and (2) broad emission with large Stokes' shift especially in the case 
Table 1. References of $n s^{2}$-type ions exhibiting luminescent property in crystals

\begin{tabular}{|c|c|c|c|}
\hline$(\mathrm{ns})^{2}$ & Ion species & Alkali halides 3$), 4)$ & Oxides \\
\hline \multirow{4}{*}{$(5 s)^{2}$} & $\mathrm{Sn}^{2+}$ & $\mathrm{NaCl}^{5)} \mathrm{KCl}^{5)} \mathrm{RbCl}^{5)}$ & \multirow{4}{*}{$\begin{array}{c}\mathrm{Ca}_{3}\left(\mathrm{PO}_{4}\right)_{2},{ }^{8} \mathrm{Sr}_{2} \mathrm{P}_{2} \mathrm{O}_{7},{ }^{9)} \\
\left.\mathrm{SrB}_{6} \mathrm{O}_{10}{ }^{10}\right) \\
\mathrm{Ca}_{5}\left(\mathrm{PO}_{4}\right)_{3}(\mathrm{~F}, \mathrm{Cl})^{2},{ }^{11)-13)} \\
\left.\mathrm{YPO}_{4}{ }^{14}\right)\end{array}$} \\
\hline & & & \\
\hline & $\mathrm{Sb}^{3+}$ & $\mathrm{KCl}^{6}{ }^{6} \mathrm{KI}^{6)}$ & \\
\hline & & & \\
\hline \multirow{4}{*}{$(6 s)^{2}$} & $\mathrm{Tl}^{+}$ & $\left.\mathrm{NaCl},{ }^{5)} \mathrm{KCl}^{5}\right)$ & \multirow{4}{*}{$\begin{array}{c}\mathrm{BaSiO}_{3}{ }^{15)} \\
(\mathrm{Ca}, \mathrm{Zn})_{3}\left(\mathrm{PO}_{4}\right)_{2}{ }^{16)} \\
\mathrm{BaSi}_{2} \mathrm{O}_{5},{ }^{15)} \mathrm{BaFSiO}_{3}{ }^{15)} \\
\mathrm{YPO}_{4}{ }^{17)}\end{array}$} \\
\hline & & & \\
\hline & $\mathrm{Pb}^{2+}$ & $\mathrm{NaCl}^{5)} \mathrm{KCl}^{5)} \mathrm{RbCl}^{5)}$ & \\
\hline & $\mathrm{Bi}^{3+}$ & $\left.\mathrm{KCl}^{7}\right)$ & \\
\hline
\end{tabular}

of $\mathrm{Sn}^{2+}$ and $\mathrm{Sb}^{3+}$ centers. Because of the large transition probability, $\mathrm{Sb}^{3+}$ doped calcium halophosphate has been used as a practical phosphor for white fluorescent lamps. ${ }^{2}$ The emission of $\mathrm{ns}^{2}$-type cation is strongly affected by the coordination field, because the emission centers possess electrons in the outermost shell in both the ground state and the excited state. ${ }^{1)}$ Considering the site distributions of amorphous glasses and crystals, it could be said that this type of emission center is suitable for amorphous glass.

\section{Preparation of $\mathrm{Sn}^{2+}$-doped zinc phosphate glass and its emission property}

We focus on glasses with the principal chemical composition $\mathrm{SnO}-\mathrm{ZnO}-\mathrm{P}_{2} \mathrm{O}_{5}$ (SZP), which have been industrially applied, owing to their low-melting properties, in the sealing of electronic devices such as LEDs. ${ }^{18), 19)}$ These glasses will be potential candidates for $\mathrm{Pb}$-containing low-melting glasses, not only because of their low-melting properties, ${ }^{20), 21)}$ but also because they contain no hazardous cations. ${ }^{22)}$ On the other hand, it was also reported that $\mathrm{Sn}$-doped $\mathrm{ZnO}-\mathrm{Al}_{2} \mathrm{O}_{3}-\mathrm{P}_{2} \mathrm{O}_{5}$ glass exhibited emission properties via the absorption of UV light. ${ }^{23)}$ In addition, tin in float glasses is used as a marker to determine the free plane by irradiation of UV light. ${ }^{24)}$ Therefore, it is expected that $\mathrm{Sn}^{2+}$. containing zinc phosphate glass can exhibit both low-melting and light emitting properties.

Among several zinc phosphate glasses, $60 \mathrm{ZnO}-40 \mathrm{P}_{2} \mathrm{O}_{5}$ glass (mole \%) has been selected as a base glass, because the structure has been examined by XPS, $\left.{ }^{25)}{ }^{31} \mathrm{PNMR},{ }^{26}\right) \mathrm{X}$-ray diffraction, ${ }^{27)}$ HPLC analysis, ${ }^{28)}$ Raman and IR, ${ }^{29)}$ and molecular dynamics calculation. ${ }^{30)}$ Starting materials of the SZP glasses were SnO, $\mathrm{ZnO}$, and $\left(\mathrm{NH}_{4}\right)_{2} \mathrm{HPO}_{4}$. Although ammonium phosphate is a commercially available solid-state chemical used as a starting material for $\mathrm{P}_{2} \mathrm{O}_{5}$, it has often been observed that the used crucible is damaged during the conventional melt process. ${ }^{31)}$ This is a clear sign that these glasses contain $\mathrm{Al}_{2} \mathrm{O}_{3}$ or $\mathrm{SiO}_{2}$ eluted from the crucible, which is likely to affect the physical properties of the obtained glass and renders the glass composition less certain. $^{32), 33)}$ Although SZP glasses are prepared using either alumina or platinum crucibles, it would be desirable to establish a preparation scheme using ammonium phosphate with a $\mathrm{Pt}$ crucible for the refined design. We have demonstrated that a sintering process $\left(\sim 800^{\circ} \mathrm{C}\right)$ using $\mathrm{ZnO}$ and $\left(\mathrm{NH}_{4}\right)_{2} \mathrm{HPO}_{4}$, in which zinc phosphate crystallites such as $\alpha-\mathrm{Zn}_{2} \mathrm{P}_{2} \mathrm{O}_{7}$ was formed to reduce amounts of $\mathrm{OH}$ groups, is the key to prevent damage to a Pt crucible. ${ }^{34)}$ Therefore, this process is important for the fabrication of contaminant-free phosphate glass using ammonium phosphate as a starting material.

The colorless SZP glasses prepared by a melt-quenching method show the glass transition temperatures, $T_{\mathrm{g}} \mathrm{s}$, that are less a

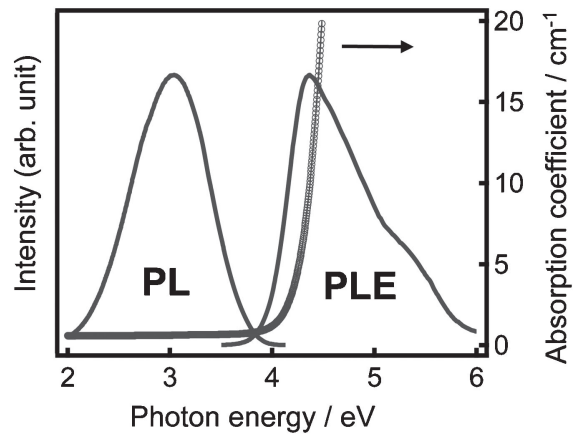

b

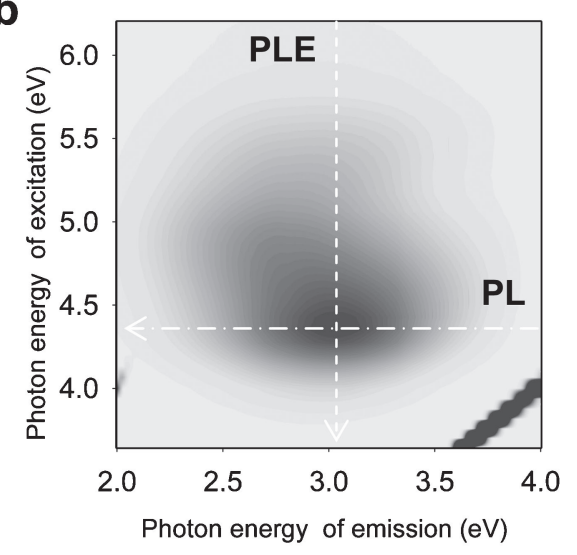

Intensity (arb. units)

low $\longleftarrow$ $\longrightarrow$ high

Fig. 2. Optical property of the $5 \mathrm{SnO}-55 \mathrm{ZnO}-40 \mathrm{P}_{2} \mathrm{O}_{5}$ glass. (a) Normalized PL and PLE spectra of the glass together with absorption spectrum of the glass. (b) Contour plot of the glass using an intensity axis on a linear scale.

than $420^{\circ} \mathrm{C}$. The $T_{\mathrm{g}}$ increases with decreasing amounts of $\mathrm{P}_{2} \mathrm{O}_{5}$ and $\mathrm{SnO}$. Figure 2(a) shows normalized photoluminescence (PL) and PL excitation (PLE) spectra of the 5SnO-55ZnO$40 \mathrm{P}_{2} \mathrm{O}_{5}$ glass together with its absorption spectrum. Comparison of the absorption spectrum with the PLE spectrum shows that the strongest emission spectrum is obtained by excitation using the wavelength of the optical band edge. Through examination of the PL properties of other SZP glasses, it is found that both the maximum PLE position that induced the maximum PL intensity and the optical band gap are blue shifted with decreasing amounts of $\mathrm{SnO}$. Since $60 \mathrm{ZnO}-40 \mathrm{P}_{2} \mathrm{O}_{5}$ glass shows no emission, it is indicated that the emission origin in the SZP glasses is the Sn species. Figure 2(b) shows a contour plot of the $5 \mathrm{SnO}-55 \mathrm{ZnO}-$ $40 \mathrm{P}_{2} \mathrm{O}_{5}$ glass with the photon energy of excitation (ordinate) and emission (abscissa), using an intensity axis on a linear scale. A broad emission is observed at the UV light excitation of $4.1-4.5 \mathrm{eV}(300-275 \mathrm{~nm})$, and the Stokes shift is about $1.3 \mathrm{eV}$. The photon energy for excitation decreases with increasing amounts of $\mathrm{SnO}$, whereas the quantum efficiency $(\mathrm{QE})$ reaches a maximum near $2.5 \mathrm{~mol} \% \mathrm{Sn}$. Notably, transparent $2.5 \mathrm{SnO}-$ $57.5 \mathrm{ZnO}-40 \mathrm{P}_{2} \mathrm{O}_{5}$ glass shows a maximum emission of the $\mathrm{QE}$ (over $80 \%$ ) without any additives, such as RE cations. ${ }^{35}$ ) This tendency is roughly correlated with the change in the chromatic coordination of the glass. Figure 3 shows the chromaticity coordinates of the SZP glasses together with photographs of (1) $40 \mathrm{SnO}-30 \mathrm{ZnO}-30 \mathrm{P}_{2} \mathrm{O}_{5}$, (2) $30 \mathrm{SnO}-30 \mathrm{ZnO}-40 \mathrm{P}_{2} \mathrm{O}_{5}$, and (3) 


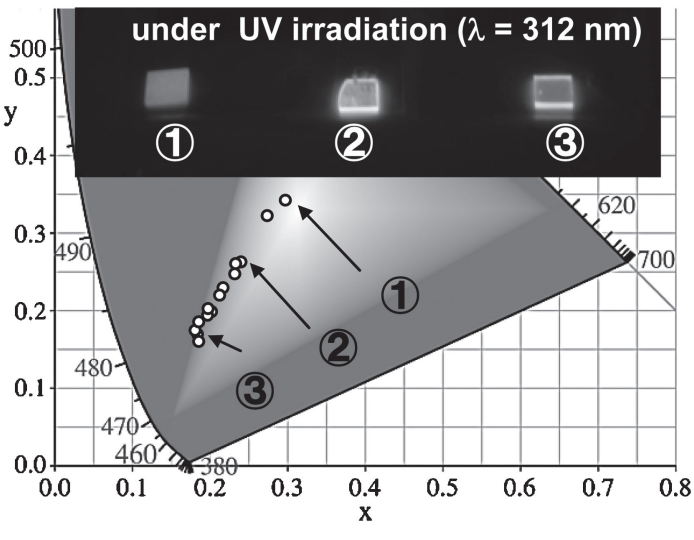

Fig. 3. Chromaticity coordinates of the $\mathrm{SnO}-\mathrm{ZnO}-\mathrm{P}_{2} \mathrm{O}_{5}$ glasses. Inset shows a photograph of (1) $40 \mathrm{SnO}-30 \mathrm{ZnO}-30 \mathrm{P}_{2} \mathrm{O}_{5}$ glass, (2) $20 \mathrm{SnO}-$ $30 \mathrm{ZnO}-40 \mathrm{P}_{2} \mathrm{O}_{5}$ glass, and (3) $5 \mathrm{SnO}-55 \mathrm{ZnO}-40 \mathrm{P}_{2} \mathrm{O}_{5}$ glass under exposure to a wavelength of UV light $(\lambda=312 \mathrm{~nm})$. Tendency of the $\mathrm{QE}$ value is roughly correlated with that of chromatic coordination of the glass.

$5 \mathrm{SnO}-55 \mathrm{ZnO}-40 \mathrm{P}_{2} \mathrm{O}_{5}$. Glass (1) exhibits a weak white emission, whereas glass (3) produces a strong blue emission. Because the oxidation state of $\mathrm{Sn}$ in glass (3) is estimated at $89 \pm 1 \%$ $\left(\mathrm{Sn}^{2+}\right): 11 \pm 1 \%\left(\mathrm{Sn}^{4+}\right)$ by Mössbauer spectroscopy, ${ }^{36)}$ it is expected that $\mathrm{Sn}^{2+}$ would strongly affect both the transparency and QE of the glass. It is confirmed that the PL properties are maintained after heat treatment at $T_{\mathrm{g}}+100 \mathrm{~K}$, the temperature at which most glasses offer workability in air. Moreover, no devitrification is observed in these glasses after heat treatment. The chemical durability demonstrated by the present SZP glass in the industrial formation process ensures its potential for sealing applications. It is reported that twofold-coordinated $\mathrm{Sn}$ in $\mathrm{SiO}_{2}$ shows two emission bands: an $\alpha$-band [singlet $\left(S_{1}\right)$-singlet $\left(S_{0}\right)$, $\sim 4.1 \mathrm{eV}$ ] and a $\beta$-band [triplet $\left.\left(T_{1}\right)-\operatorname{singlet}\left(S_{0}\right), \sim 3.1 \mathrm{eV}\right] .{ }^{37), 38)}$ Since the emission decay constant $\tau_{1 / \mathrm{e}}$ was $4.5 \mu \mathrm{s}$, which is a typical decay time for $T_{1}-S_{0}$ relaxation, the observed emission is probably due to the $T_{1}-S_{0}$ relaxation of twofold $\mathrm{Sn}^{2+}$ center. On the other hand, the QE decreased as the amount of $\mathrm{Sn}$ in the glass increased, which is an indication of concentration quenching. Because the glass showed stable emission properties after the formation process, it is a promising candidate for use as a sealing material for various types of optoelectronic devices.

\section{Comparison of $\mathrm{Sn}^{2+}$ and $\mathrm{Sb}^{3+}$ emission centers in zinc phosphate glass}

As mentioned above, $\mathrm{Sb}^{3+}, \mathrm{Mn}^{2+}$-codoped calcium halophosphate is a practical phosphor for white fluorescent lamps. ${ }^{2)}$ On the other hand, $\mathrm{Sb}_{2} \mathrm{O}_{3}$ is used as a fining agent in glass preparation because its oxidation state can be changed upon the release or capture of oxygen in the glass melt. ${ }^{39)} \mathrm{Sb}^{3+}$ has thus far received little attention as an emission center in conventional glass science, although the emission of $\mathrm{Sb}^{3+}$ has been described. ${ }^{40), 41)}$ Since it was reported that $\mathrm{Sb}^{3+}$-doped zinc phosphate was also a potential substitute for $\mathrm{Pb}$-based glasses in sealing applications, ${ }^{42)}$ it is worthwhile to examine $\mathrm{Sb}^{3+}$-doped $\mathrm{ZnO}-\mathrm{P}_{2} \mathrm{O}_{5}$ glass to discuss the differences between $\mathrm{Sn}^{2+}$ and $\mathrm{Sb}^{3+}$ emission centers. ${ }^{43)}$

One of the differences between the $\mathrm{Sb}^{3+}$ and $\mathrm{Sn}^{2+}$ emission centers is effect of a preheating treatment before glass melting on coloration of the glasses. If the starting materials are preheated at $500^{\circ} \mathrm{C}$, the obtained $\mathrm{Sb}^{3+}$-doped glass is transparent as shown in Fig. 4(a). On the other hand, the formation of $\mathrm{Sb}$ nanoparticles is observed in the glass preheated at $300^{\circ} \mathrm{C}$, as shown in Fig. 4(b). a

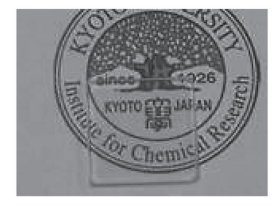

b
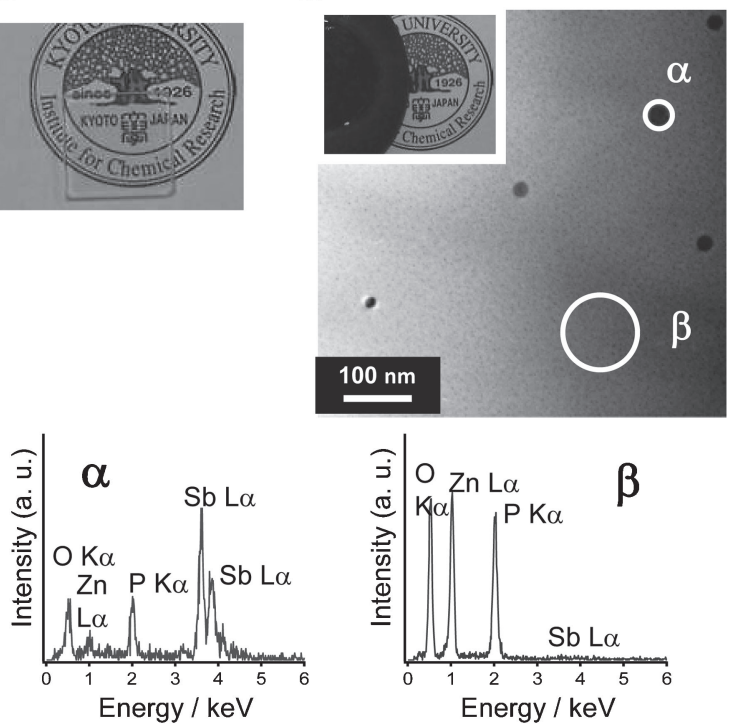

Fig. 4. (a) Photograph of the $1.0 \mathrm{SbO}_{3 / 2}-60 \mathrm{ZnO}-40 \mathrm{P}_{2} \mathrm{O}_{5}$ glass prepared by $1100^{\circ} \mathrm{C}$ melting with pre-heat-treatment at $500^{\circ} \mathrm{C}$. (b) TEM image of the $1.0 \mathrm{SbO}_{3 / 2}-60 \mathrm{ZnO}-40 \mathrm{P}_{2} \mathrm{O}_{5}$ glass prepared by $1100^{\circ} \mathrm{C}$ melting with pre-heat-treatment at $300^{\circ} \mathrm{C}$. EDX patterns of two parts $(\alpha)(\beta)$ are also shown.

Since reducing conditions have been reported to facilitate the precipitation of metal nanoparticles in glass materials, ${ }^{44), 45)}$ it is speculated that $\mathrm{Sb}^{3+}$-doped glass is easily affected by the reductive species to change the valence during melt quenching, which is not observed in the $\mathrm{Sn}^{2+}$-doped glass.

Figure 5(a) shows the normalized PL and PLE spectra of the $x \mathrm{SbO}_{3 / 2}-60 \mathrm{ZnO}-40 \mathrm{P}_{2} \mathrm{O}_{5}$ glasses. The $1.0 \mathrm{SbO}_{3 / 2}-60 \mathrm{ZnO}-$ $40 \mathrm{P}_{2} \mathrm{O}_{5}$ glass shows the strongest emission intensity among these glasses. The PL spectra most likely consists of two bands at 2.95 and $2.11 \mathrm{eV}$, and the peak area ratio of the peak at $2.11 \mathrm{eV}$ decreases with increasing amounts of $\mathrm{SbO}_{3 / 2}$. Comparison of the absorption spectrum with the PLE spectrum shows that the strongest emission is obtained by excitation using the wavelength of the optical band edge, and the optical band edges and the PLE peak energies of the $x \mathrm{SbO}_{3 / 2}-60 \mathrm{ZnO}-40 \mathrm{P}_{2} \mathrm{O}_{5}$ glasses are red shifted with increasing amounts of $\mathrm{SbO}_{3 / 2}$, which is also observed in the $\mathrm{SnO}-\mathrm{ZnO}-\mathrm{P}_{2} \mathrm{O}_{5}$ glass. However, although both emission centers adopt the $5 \mathrm{~s}^{2}$ electron configuration, the emission properties of the Sb-doped glass are quite different from those of the $\mathrm{Sn}^{2+}$-doped glass. One of the differences between the $\mathrm{Sb}^{3+}$ and $\mathrm{Sn}^{2+}$ emission centers is the amount of added species. The $\mathrm{SbO}_{3 / 2}-\mathrm{ZnO}-\mathrm{P}_{2} \mathrm{O}_{5}$ glass can contain less than $2 \mathrm{~mol} \% \mathrm{Sb}^{3+}$ without any decrease in transparency, as opposed to the previous $\mathrm{Sn}^{2+}$-doped glasses that can contain more than $5 \mathrm{~mol} \% \mathrm{Sn}^{2+}{ }^{46)}$ The broad absorption tail in the $2 \mathrm{SbO}_{3 / 2}$ $60 \mathrm{ZnO}-40 \mathrm{P}_{2} \mathrm{O}_{5}$ indicates defects due to the presence of excess $\mathrm{Sb}$ cations. Figures 5(b) and 5(c) show the PL-PLE contour plots of $1.0 \mathrm{SbO}_{3 / 2}-60 \mathrm{ZnO}-40 \mathrm{P}_{2} \mathrm{O}_{5}$ glass and $1.0 \mathrm{SbO}_{3 / 2}-60 \mathrm{ZnO}-$ $40 \mathrm{P}_{2} \mathrm{O}_{5}$ glass, respectively. The emission color of the $\mathrm{Sb}^{3+}$-doped glass is slightly pink, and is different from the blue color derived from the $\mathrm{Sn}^{2+}$-doped glass. As shown in Fig. 5(b), the emission at the maximum peak intensity for $\mathrm{Sb}^{3+}$ is located at $2.97 \mathrm{eV}$, with a bandwidth of about $1.5 \mathrm{eV}$. Although the photon energy for excitation of $\mathrm{Sb}^{3+}$ is higher than that of $\mathrm{Sn}^{2+}$, the emission of $\mathrm{Sb}^{3+}$ corresponds to a lower emission band energy and a broader bandwidth than that of $\mathrm{Sn}^{2+}$, as shown in Fig. 5(c). In addition, 
a

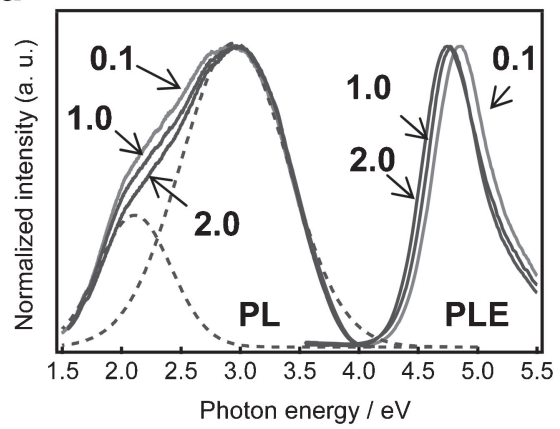

b

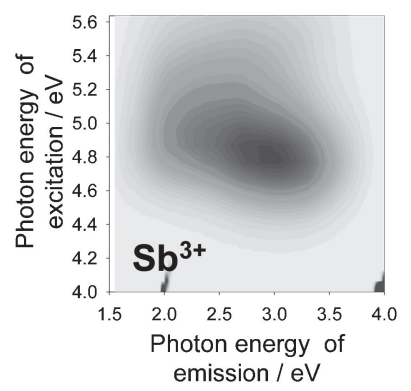

C

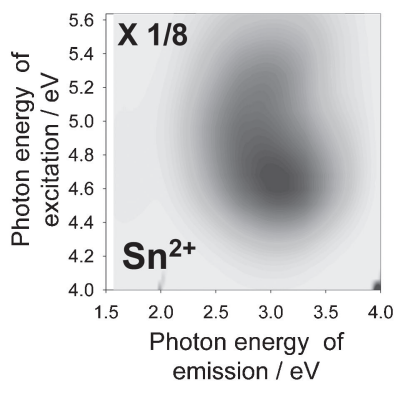

Intensity (arb. units)

low $\leftarrow$ high

Fig. 5. Normalized PL and PLE spectra of $x \mathrm{SbO}_{3 / 2}-60 \mathrm{ZnO}-40 \mathrm{P}_{2} \mathrm{O}_{5}$ glasses. Dotted lines indicate the deconvoluted emission bands of the $2.0 \mathrm{SbO}_{3 / 2}-60 \mathrm{ZnO}-40 \mathrm{P}_{2} \mathrm{O}_{5}$ glass. PL-PLE contour plot of the $1.0 \mathrm{SbO}_{3 / 2}-$ $60 \mathrm{ZnO}-40 \mathrm{P}_{2} \mathrm{O}_{5}$ glass (b) and the $1.0 \mathrm{SnO}-60 \mathrm{ZnO}-40 \mathrm{P}_{2} \mathrm{O}_{5}$ glass (c).

Table 2. Emission properties of the $1.0 \mathrm{SbO}_{3 / 2}-60 \mathrm{ZnO}-40 \mathrm{P}_{2} \mathrm{O}_{5}$ and the $1.0 \mathrm{SnO}-60 \mathrm{ZnO}-40 \mathrm{P}_{2} \mathrm{O}_{5}$ glasses. These glasses were prepared by $1100^{\circ} \mathrm{C}$ melting with pre-heat-treatment at $500^{\circ} \mathrm{C}$

\begin{tabular}{ccc}
\hline $\mathrm{ns}^{2}$ emission center & $\mathrm{Sb}^{3+}$ & $\mathrm{Sn}^{2+}$ \\
\hline Peak energy of excitation/eV & 4.77 & 4.61 \\
Peak energy of emission/eV & 2.97 & 3.06 \\
Band width of emission/eV & $\sim 1.5$ & $\sim 1.0$ \\
$\tau_{1 / \mathrm{e}} / \mu \mathrm{s}$ & 2.5 & 5.3 \\
\hline
\end{tabular}

the $1.0 \mathrm{SbO}_{3 / 2}-60 \mathrm{ZnO}-40 \mathrm{P}_{2} \mathrm{O}_{5}$ glass shows non-exponential decay with a lifetime $\left(\tau_{1 / \mathrm{e}}\right)$ of $2.5 \mu \mathrm{s}$, which is half the lifetime of the $1.0 \mathrm{SnO}-60 \mathrm{ZnO}-40 \mathrm{P}_{2} \mathrm{O}_{5}$ glass, in which single exponential-like decay is observed. The non-exponential intensity decay of $\mathrm{Sb}^{3+}$ indicates that a quenching site exists in the glass. The broad emission of $\mathrm{Sb}^{3+}$ is suitable for white light emission via excitation by a deep-UV LED. As shown in Table 2, the $\mathrm{Sn}^{2+}$ emission center is more favorable as a longer excitation light source, whereas emission of $\mathrm{Sb}^{3+}$ is advantageous from the viewpoint of broader emissions capable of achieving high color rendering. However, from viewpoint of practical application, emission intensity of $\mathrm{Sb}^{3+}$ is much weaker than that of $\mathrm{Sn}^{2+}$, which confirm that $\mathrm{Sn}^{2+}$ emission center is the most suitable for the present phosphate glass system.

\section{White light emission of $\mathrm{Sn}^{2+}, \mathrm{Mn}^{2+}$-codoped zinc phosphate glass}

Since the SZP glasses show a broad and strong blue emission, it is expected that a white light emission can be attained by the addition of $\mathrm{Mn}^{2+}$ cation, similar to the $\mathrm{Sb}^{3+}, \mathrm{Mn}^{2+}$-codoped calcium halophosphate. ${ }^{2)}$ By preparation of a series of $\mathrm{Sn}^{2+}, \mathrm{Mn}^{2+}$ a

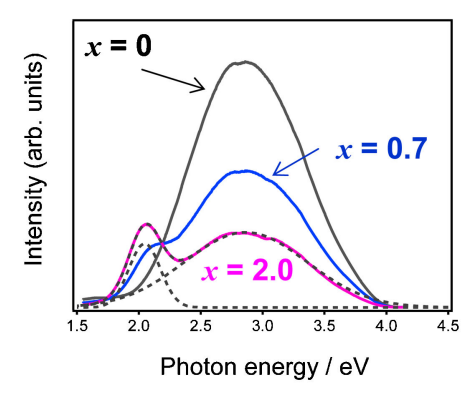

b

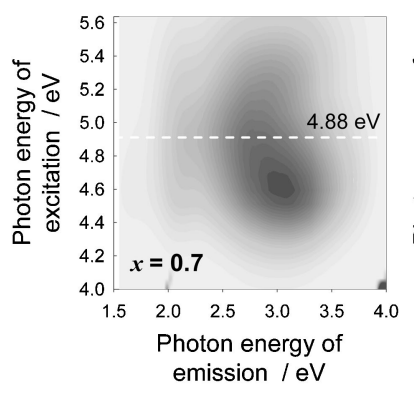

C

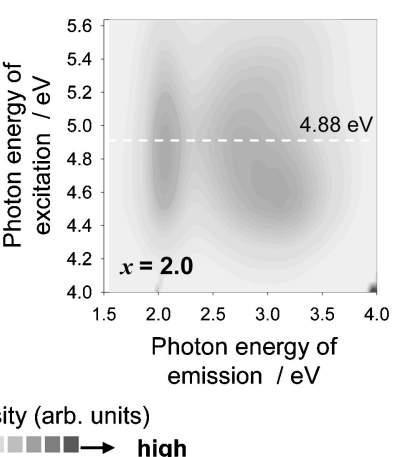

Fig. 6. (Color online) (a) $\mathrm{PL}$ spectra of the $\mathrm{MnO}-2.5 \mathrm{SnO}-57.5 \mathrm{ZnO}-$ $40 \mathrm{P}_{2} \mathrm{O}_{5}$ glasses excited by $4.88 \mathrm{eV}$. PL spectra can be deconvoluted into two bands: $2.86 \mathrm{eV}\left(\mathrm{Sn}^{2+}\right)$ and $2.05 \mathrm{eV}\left(\mathrm{Mn}^{2+}\right)$. PL-PLE Contour plots of the $2.5 \mathrm{SnO}-57.5 \mathrm{ZnO}-40 \mathrm{P}_{2} \mathrm{O}_{5}$ glasses with different amounts of $\mathrm{MnO}$. (b) 0.7 , and (c) $2.0 \mathrm{~mol} \%$. Linear scale is used for the intensity axis.

codoped zinc phosphate glasses, we demonstrate that a white fluorescent lamp is attained by combining UV light and a RE-free amorphous glass phosphor. ${ }^{47), 48)}$

Figure 6(a) shows the PL spectra of the $x \mathrm{MnO}-2.5 \mathrm{SnO}-$ $57.5 \mathrm{ZnO}-40 \mathrm{P}_{2} \mathrm{O}_{5}$ glass excited by a photon energy of $4.88 \mathrm{eV}$ $(254 \mathrm{~nm})$. This glass composition consisted of $\mathrm{MnO}$ and the SZP glass composition, which showed the maximum QE. ${ }^{35)}$ The emission spectra consist of two broad bands: a $\mathrm{Sn}^{2+}$ emission center at $2.86 \mathrm{eV}$ and a $\mathrm{Mn}^{2+}\left(3 \mathrm{~d}^{5}\right)$ center at $2.05 \mathrm{eV}$. The emission decay constants $\tau_{1 / \mathrm{e}}$ of the $\mathrm{Sn}$ emissions $(2.86 \mathrm{eV})$ of the $x \mathrm{MnO}-2.5 \mathrm{SnO}-57.5 \mathrm{ZnO}-40 \mathrm{P}_{2} \mathrm{O}_{5}$ glasses $(x=0,0.7$, and 2.0$)$ at room temperature are $4.5 \mu \mathrm{s}(x=0), 3.5 \mu \mathrm{s}(x=0.7)$, and $2.1 \mu \mathrm{s}$ $(x=2.0)$, with an excitation wavelength of $280 \mathrm{~nm}$. Since the shape of the decay curves changes from exponential to nonexponential, it can be concluded that the $\mathrm{Sn}^{2+}$ center plays roles both in the emission centers and in the energy donors to $\mathrm{Mn}^{2+}$. Figures 6(b) and 6(c) show PL-PLE contour plots of the $x \mathrm{MnO}-$ $2.5 \mathrm{SnO}-57.5 \mathrm{ZnO}-40 \mathrm{P}_{2} \mathrm{O}_{5}$ glasses $(x=0.7$, and 2.0$)$. The mapping suggests that the coordination state of $\mathrm{Sn}^{2+}$ was almost unchanged in the zinc phosphate glass by the addition of $\mathrm{Mn}^{2+}$, although the emission intensity is decreased by energy transfer. Comparing the absorption spectrum with the PLE spectrum, the present excitation at $4.88 \mathrm{eV}$, which is higher than the optical band edge, is the most suitable position for the $\mathrm{Mn}^{2+}$ center but not for the $\mathrm{Sn}^{2+}$ center. The broad emission suggests that different emission colors can be obtained from the same glass phosphor by changing the excitation light source. Figure 7 shows a photograph of the $x \mathrm{MnO}-2.5 \mathrm{SnO}-57.5 \mathrm{ZnO}-40 \mathrm{P}_{2} \mathrm{O}_{5}$ glass under UV light irradiation $(4.88 \mathrm{eV})$, and the chromaticity coordinates. It is notable that these glasses shows a high normalized QE value, comparable to that of practical $\mathrm{MgWO}_{4}$. This value enables us to confirm the potential application of the 


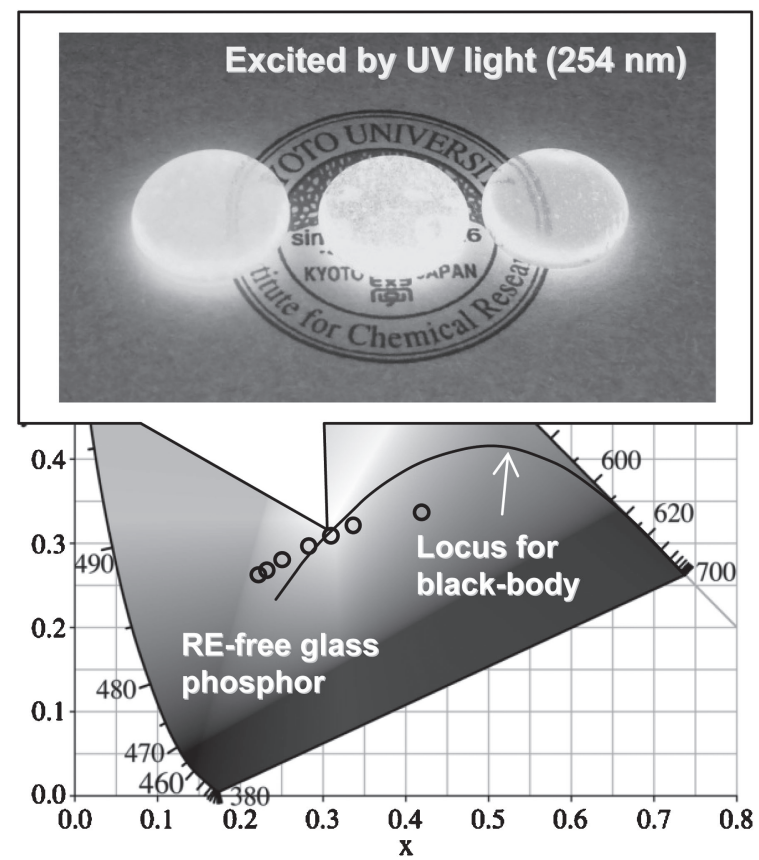

Fig. 7. Chromaticity coordinates of the MnO-doped 2.5SnO-57.5ZnO$40 \mathrm{P}_{2} \mathrm{O}_{5}$ glasses. These glasses were excited by a photon energy of $4.88 \mathrm{eV}$ $(254 \mathrm{~nm})$. The glass phosphor can attain color tuning with a wide range of color temperatures by one monolithic transparent glass. Inset shows photograph of the glass phosphors $(x=0,0.7,2.0)$ with irradiation of deep UV light $(254 \mathrm{~nm})$.

obtained RE-free glass as a phosphor with a high QE. On the other hand, it is also noteworthy that the color coordination positions continuously changes from blue to red with the addition of $\mathrm{MnO}$. In particular, several glasses satisfied the white light emission condition without the RE cation. As shown in Fig. 6(a), the blue color $\left(\mathrm{Sn}^{2+}\right)$ decreased with increasing amounts of $\mathrm{Mn}^{2+}$.

From the obtained results, we suggest that the basicity of the glass affects both the emission center and the resulting emission color. Since the basicity of oxide glasses can be tailored by a great variety of chemical compositions, the emission color can also be controlled over a wide range. The present results indicate that the $\mathrm{Mn}$-doped $\mathrm{SnO}-\mathrm{ZnO}-\mathrm{P}_{2} \mathrm{O}_{5}$ glasses will be novel glass-based materials that possess emission properties. Although the present glass shows white light emission that is similar to the calcium halophosphate crystals, there are several large differences between the two. First, for a greater number of emission centers, $\mathrm{Sn}^{2+}$ can be doped in the glass. Second, various kinds of elements can be added to the glass to control the emission properties as well as to improve mechanical or thermal properties. Third, monolithic materials can reduce optical loss due to scattering at the interface. Moreover, transparent emission materials will meet novel industrial needs. Therefore, such materials can be industrially applied as sealing materials for electronic devices such as LEDs, because these glasses also possess low-melting properties.

Here, we have again emphasized the advantage of combining these low-melting glass phosphors with a next-generation deepUV LED. From the viewpoint of chemical stability, an inorganic low-melting glass is a candidate for a practical sealant in deepUV LEDs. Since the light conversion is attained by the monolithic amorphous material without an internal interface, the color change of device by time-dependent deterioration of each phosphor or sealant is inherently prevented. Although deep-
UV LEDs are not yet commercially available, recent developments clearly suggest the possibility for their realization in the near future. ${ }^{49), 50)}$ The next-generation white LED indicates the realization of $\mathrm{Hg}$-free white fluorescent lamps. The important point of our results is that amorphous oxide glasses possessing random structures demonstrate high $\mathrm{QE}$ values comparable to conventional crystalline phosphors. Although the emission of $\mathrm{Sn}^{2+}$ can be explained by the conventional $\mathrm{ns}^{2}$-type emission mechanism, there may exist a mechanism characteristic of amorphous material. Unlike RE cations, which exhibit high QE values because of the small influence of phonons, the $\mathrm{ns}^{2}$-type centers in our glasses have many uncertain points. Although the mechanism of the emissions has not been fully clarified yet, the present RE-free glass phosphors are very fascinating materials from the viewpoint of unique emission mechanisms in a random matrix.

\section{Summary and future prospects}

The UV-excited light emission of RE-free zinc phosphate glasses has been demonstrated. Notably, a high efficiency, comparable to practical crystalline phosphors, is attained in the amorphous material. The emission, consisting of broad bands, can be tailored by the addition of another emission center such as $\mathrm{Mn}^{2+}$ or by changing the local coordination field (i.e., the chemical composition of the mother glass) of $\mathrm{Sn}^{2+}$. These tuning is the forte of oxide glass, and it is characteristic of glass-based device. Recently, our group has reported $\mathrm{Sn}^{2+}$-doped oxide glasses exhibit scintillation property, which is another application of this material. ${ }^{51)}$ On the other hand, preparation of Sn-doped thin film is also examined for application of transparent plane emission device without RE. ${ }^{52)}$ Therefore, RE-free inorganic amorphous materials possessing emission properties will be required for novel, practical optical devices. Since the emission mechanism as well as the local coordination state of $\mathrm{Sn}^{2+}$ in oxide glass has not been clarified yet, further study is needed for understanding the basic science to improve the performance. The author thus believes that $\mathrm{ns}^{2+}$-type cation containing oxide glass will attract much attention from both scientific and industrial viewpoints.

Acknowledgments The author gratefully acknowledges Prof. Takumi Fujiwara (Tohoku University), Dr. Syuji Matsumoto (Asahi Glass Co. Ltd.), and Prof. Toshinobu Yoko (Kyoto University) with deepest appreciation. The author also expresses great appreciation for Prof. Takayuki Komatsu (Nagaoka University of Technology), Prof. Masahide Takahashi (Osaka Prefecture University) and Prof. Tamejiro Hiyama (Chuo University). This work was financially supported by Adaptable and seamless technology transfer program through target-driven R\&D, Japan Science and Technology Agency, Asahi Glass Foundation, Inamori Foundation, Kazuchika Okura Memorial Foundation, Yazaki Memorial Foundation for Science and Technology, and Research Institute for Production Development. The author thanks Dr. Yoshihiro Takahashi (Tohoku University), Dr. Atsushi Wakamiya (Kyoto University), Dr. Yasuhiro Yamada (Kyoto University), and Dr. Yomei Tokuda (Kyoto University) for their assistance for research accomplishment.

\section{References}

1) W. M. Yen, S. Shionoya and H. Yamamoto, "Phosphor handbook", 2nd edition, CRC Press, Boca Raton (2007).

2) A. Wachtel, J. Electrochem. Soc., 113, 128-134 (1966).

3) F. Seitz, J. Chem. Phys., 6, 150-162 (1938)

4) A. Ranfagni, D. Magnai, M. Bacci, G. Viliani and M. P. Fontana, Adv. Phys., 32, 823-905 (1983). 
5) Y. Toyozawa and M. Inoue, J. Phys. Soc. Jpn., 21, 1663-1679 (1966).

6) K. O. Choi, S. W. Lee, H. K. Bae, S. H. Jung, C. K. Chang and J. G. Kang, J. Chem. Phys., 94, 6420-6428 (1991).

7) J. G. Kang, H. M. Yoon, G. M. Chun, Y. D. Kim and T. Tsuboi, J. Phys.: Condens. Matter, 6, 2101-2116 (1994).

8) H. Donker, W. M. A. Smit and G. Blasse, J. Electrochem. Soc., 136, 3130-3135 (1989).

9) R. C. Ropp and R. W. Mooney, J. Electrochem. Soc., 107, 1520 (1960).

10) M. Leskelä, T. Koskentalo and G. Blasse, J. Solid State Chem., 59, 272-279 (1985).

11) K. H. Butler and C. W. Jerome, J. Electrochem. Soc., 97, 265270 (1950)

12) T. S. Davis, E. R. Kreidler, J. A. Parodi and T. F. Soules, J. Lumin., 4, 48-62 (1971).

13) T. F. Soules, R. L. Bateman, R. A. Hewes and E. R. Kreidler, Phys. Rev. B, 7, 1657-1667 (1973).

14) E. W. J. L. Omen, W. M. A. Smit and G. Blasse, Phys. Rev. B, 37, 18-26 (1988).

15) R. H. Clapp and R. J. Ginther, J. Opt. Soc. Am., 37, 355-362 (1947).

16) R. Nagy, R. W. Wollentin and C. K. Lui, J. Electrochem. Soc., 97, 29-32 (1950).

17) T. J-Stel, P. Huppertz, W. Mayr and D. U. Wiechert, J. Lumin., 106, 225-233 (2004).

18) S. Matsumoto, N. Nakamura and N. Wada: WO 2009/088086 (2009).

19) S. Matsumoto, Y. Osaki and N. Nakamura: WO 2008/146886 (2008).

20) R. Morena, J. Non-Cryst. Solids, 263-264, 382-387 (2000).

21) B. G. Aitken, D. C. Bookbinder, M. E. Greene and R. M. Morena, U.S. 5246890 (1993).

22) H. S. Liu, P. Y. Shih and T. S. Chin, Phys. Chem. Glasses, 37, 227-235 (1996).

23) J. G. Hooley, US 2400147 (1946).

24) P. D. Townsend, N. Can, P. J. Chandler, B. W. Farmery, R. Lopez-Heredero, A. Peto, L. Salvin, D. Underdown and B. Yang, J. Non-Cryst. Solids, 223, 73-85 (1998).

25) E. C. Onyiriuka, J. Non-Cryst. Solids, 163, 268-273 (1993).

26) R. K. Brow, D. R. Tallant, S. T. Myers and C. C. Phifer, J. NonCryst. Solids, 191, 45-55 (1995).

27) G. Walter, U. Hoppe, T. Baade, R. Kranold and D. Stachel, J. Non-Cryst. Solids, 217, 299-307 (1997).

28) B. C. Sales, J. U. Otaigbe, G. H. Beall, L. A. Boatner and J. O. Ramey, J. Non-Cryst. Solids, 226, 287-293 (1998).

29) G. L. Saout, F. Fayon, C. Bessada, P. Simon, A. Blin and Y.
Vaills, J. Non-Cryst. Solids, 293-295, 657-662 (2001).

30) B. C. Tischendorf, T. M. Alam, R. T. Cygan and J. U. Otaigbe, J. Non-Cryst. Solids, 316, 261-272 (2003).

31) M. B. Volf, "Chemical Approach to Glass", Elsevier, Amsterdam, Netherlands (1984) p. 208.

32) H. Masai, T. Ueno, Y. Takahashi and T. Fujiwara, J. Am. Ceram. Soc., 94, 2452-2457 (2011).

33) H. Masai, T. Ueno, T. Toda, Y. Takahashi and T. Fujiwara, J. Non-Cryst. Solids, 356, 3080-3084 (2010).

34) H. Hasai, T. Tanimoto, T. Fujiwara, S. Matsumoto, Y. Takahashi, Y. Tokuda and T. Yoko, J. Non-Cryst. Solids, 358, 265-269 (2012)

35) H. Masai, Y. Takahashi, T. Fujiwara, S. Matsumoto and T. Yoko, Appl. Phys. Express, 3, 082102 (2010).

36) D. Benne, C. Rüssel, M. Menzel and K. D. Becker, J. NonCryst. Solids, 337, 232-240 (2004).

37) L. Skuja, J. Non-Cryst. Solids, 149, 77-95 (1992).

38) T. Hayakawa, T. Enomoto and M. Nogami, Jpn. J. Appl. Phys., 45, 5078-5083 (2006).

39) M. B. Volf, "Chemical approach to glass", Elsevier, Amsterdam (1984) pp. 470-476.

40) N. J. Keidl, J. Opt. Soc. Am., 35, 249-257 (1945).

41) S. Parke and R. S. Webb, J. Phys. D, 4, 825-828 (1971).

42) B. Zhang, Q. Chen, L. Song, H. Li and F. Hou, J. Am. Ceram. Soc., 91, 2036-2038 (2008).

43) H. Masai, S. Matsumoto, T. Fujiwara, Y. Tokuda and T. Yoko, J. Am. Ceram. Soc., 95, 862-865 (2012).

44) H. Masai, Y. Takahashi, T. Fujiwara, Y. Tokuda and T. Yoko, J. Appl. Phys., 108, 023503 (2010).

45) H. Masai, K. Hamaguchi, Y. Suzuki, K. Iwasaki, R. Ihara, Y. Takahashi and T. Fujiwara, J. Appl. Phys., 111, 123513 (2012).

46) H. Masai, T. Tanimoto, T. Fujiwara, S. Matsumoto, Y. Tokuda and T. Yoko, Opt. Express, 20, 27319-27326 (2012).

47) H. Masai, T. Fujiwara, S. Matsumoto, Y. Takahashi, K. Iwasaki, Y. Tokuda and T. Yoko, Opt. Lett., 36, 2868-2870 (2011).

48) H. Masai, T. Fujiwara, S. Matsumoto, Y. Takahashi, K. Iwasaki, Y. Tokuda and T. Yoko, J. Ceram. Soc. Japan, 119, 726-730 (2011).

49) T. Oto, R. G. Banal, K. Kataoka, M. Funato and Y. Kawakami, Nature Photonics, 4, 767-771 (2010).

50) H. Hirayama, S. Fujikawa, Y. Tsukada and N. Kamada, Oyo Buturi, 80, 319-324 (2011) [in Japanese].

51) H. Masai, T. Yanagida, Y. Fujimoto, M. Koshimizu and T. Yoko, Appl. Phys. Lett., 101, 191906 (2012).

52) H. Masai, H. Miyata, Y. Tokuda and T. Yoko, J. Am. Ceram. Soc. DOI: $10.1111 /$ jace. 12158 .

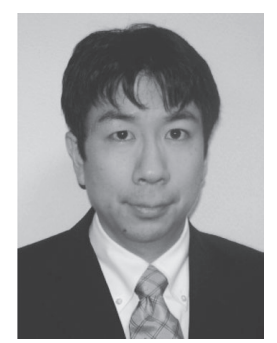

Hirokazu Masai received his Ph. D in Department of Molecular Engineering at Kyoto University (2005) with a dissertation on organic-inorganic hybrid materials. He joined Department of Applied Physics at Tohoku University as an assistant professor in 2006 after postdoctoral researcher, whose research was active glass-ceramic fiber device for electro-optic application, at Nagaoka University of Technology and Tohoku University. In Tohoku University, his research dealt with glass-ceramics containing functional nano-crystallites. From 2010, He joined Institute for Chemical Research, Kyoto University as an assistant professor. His current research interests include preparation of rare earth free oxide glass phosphor and functional glass-based material for optical applications. 